\title{
Diagnostic utility of ankle-brachial index and carotid intima-media thickness as non-invasive predictors of the severity of coronary atherosclerosis
}

\section{Introduction}

Atherosclerosis had become one of the leading causes of death in the world. ${ }^{1}$ It has three main manifestations which involve coronary, cerebrovascular and peripheral arteries. Many studies had shown the association between these artery diseases, including the cerebrovascular disease, peripheral artery disease (PAD) and coronary artery disease $(\mathrm{CAD}){ }^{2}$ The association between the PAD, high risk cardiovascular events and death also has been proven. ${ }^{3}$ However, most patients with PAD were underdiagnosed because the asymptomatic clinical presentation and the physician's awareness of the disease are relatively low. ${ }^{4}$

The ankle-brachial index (ABI), as a noninvasive and simple modality, has high sensitivity and specificity for PAD diagnosis. ABI is not only useful as a diagnostic tool, but also is a powerful indicator of atherosclerotic disease in other vascular bed and prognostic modality (increased cardiovascular morbidity / mortality with low ABI). ${ }^{5,6}$ Several studies have demonstrated that patients with PAD are at increased risk of adverse cardiovascular events compared to those individuals without PAD. Consequently, there is increasing interest in $\mathrm{ABI}$ as a non-invasive tool capable of identifying subclinical atherosclerosis, including coronary artery disease (CAD). ${ }^{7,8}$ The use of ABI in peripheral arterial disease (PAD) is well established. As the same pathogenesis primarily involves coronary vasculature, ABI $(\leq 0.9$ or $<0.9)$ can also be used a predictor of cardiovascular events and death. ${ }^{9-11}$ Abnormal ABIs, both low $(<1.0)$ and a high $(\geq 1.40)$ are associated with elevated risk of cardiovascular disease. ${ }^{12}$

It's well-known that increased CIMT is a diagnostic tool in patients with stroke. CIMT is also increased in subjects with CAD. ${ }^{13-15}$ The cut-off value of CIMT varies depending on the age $\mathrm{e}^{16,17}$ and ethnicity. (18) Carotid intima-media thickness (IMT) may be measured by ultrasound, where the distance between a double- line reflex pattern representing the luminal-intimal and the medial-adventitial interfaces corresponds well with IMT measured in histological specimens. ${ }^{19}$ Thickening of the artery wall is a hallmark of atherosclerosis. It has thus been theorized that IMT measurements could aid in the prediction of cardiovascular disease (CVD) and thereby improve CVD prediction by traditional risk factors alone. However, recommendations regarding the use of carotid IMT for CVD risk prediction are conflicting. ${ }^{20}$

In this study, we compared and examined the potential efficacy of the combination of carotid US finding and ABI in predicting severity of coronary artery disease.

\section{Methods}

A cross sectional study was conducted on 60 patients from those that were investigated by coronary angiography at the coronary catheterization unit at Sohag University Hospital. Ethics committee approval and informed consent were obtained.

\author{
Clinical Paper \\ Volume II Issue I - 2018 \\ Yasser Kamal, Mohamed Elmasry, Mohamed
Elrashidy
Sohag University, Egypt
}

Correspondence: Yasser Kamal, Sohag University Hospital Sohag, Egypt, Tel 0020122397|488, Email dr.yasserkamal@gmail.com

Received: January 27, 2018 | Published: February 23, 2018

\section{Carotid US}

Using carotid US, the mean common carotid artery IMT was evaluated. High resolution B-mode, color Doppler, and pulse Doppler US of both carotid arteries were performed by an experienced sonographer with (Aplio 500; Toshiba). The sonographer and the interpreting cardiologist were blinded to the angiographic findings. Patients were examined in the supine position with their heads tilted backward. After the carotid arteries were located by transverse scans, the probe was rotated $90^{\circ}$ to obtain and record longitudinal images of bilateral carotid arteries. High-resolution images were obtained of the far wall of the bilateral common carotid arteries, internal carotid arteries, and carotid bulbs, according to the recommendations of the American Society of Echocardiography Carotid Intima-Media Thickness Task Force. ${ }^{21}$

IMT was defined as the distance between the leading edge of the lumen-intima echo and the leading edge of the media-adventitia echo (Figure 1). At least 3 measurements were taken over a 1-cm length of each common carotid artery, and measurements from both sides were averaged to obtain the mean IMT. When plaque was present in the segment used for measuring the mean IMT, the plaque thickness was averaged into the mean IMT measurement.

\section{Measurement of ABI:}

Each patient was evaluated in the supine position after resting for $5 \mathrm{~min}$. ABI was measured in each leg using a doppler ultrasound (Toshiba Apllio 500) while the patient remained in the same position. For the purpose of this analysis, the lowest ABI obtained for either leg was taken as the ABI measurement for the patient.

\section{Coronary angiography}

Selective coronary angiography was performed in all patients under local anesthesia via femoral artery using the Judkins technique using a coronary angiogram (Toshiba, INFINIX CBI). The severity 
of each lesion was assessed by quantitative coronary angiography. The results of the coronary angiography were classified into: (22) significant coronary stenosis $(\geq 50 \%)$ in at least one of the major coronary arteries \& non-significant coronary stenosis $(<50 \%)$.

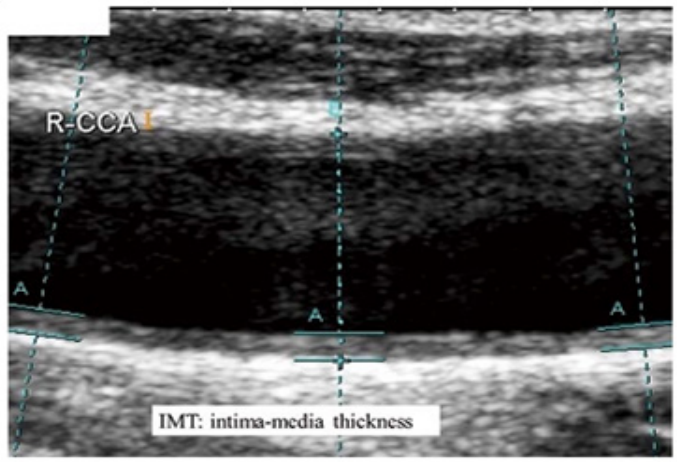

Figure 1 R-CCA (Right common carotid artery). Definition of intima-media thickness.

\section{Statistical analysis}

Continuous variables are presented as mean $\pm \mathrm{SD}$ or median Quantitative data was expressed as means \pm standard deviation.

Table 1 Patient characteristics
Qualitative data was expressed as number and percentage. ChiSquare test was used for comparison between qualitative variables. Quantitative data was tested for normality by Shapiro-Wilk test. The nonparametric Mann-Whitney U test was used for comparing two quantitative variables. Kruskal-Wallis $\mathrm{H}$ test was used for comparison between more than two quantitative variables when variables were non parametric. When data was normally distributed, ANOVA test was used. Two-sided $\mathrm{P}<0.05$ was considered significant. SPSS version 22.0 and Medcalc version 15.8.0, were used for analysis.

\section{Results}

Patient characteristics are listed in Table 1. The mean age was 69.2 years; 60 patients $(71.7 \%)$ were male, $35(58.3 \%)$ were current smokers. Patients with carotid mean IMT $\geq 0.9 \mathrm{~mm}$ had significantly more severe coronary artery disease than patients without thickening (mean IMT $>0.9 \mathrm{~mm}$ ). Similarly, patients with low ABI $(<0.9)$ had significantly more severe coronary artery disease than patients with $\mathrm{ABI} \geq 0.9$. When the patients were divided into 4 groups (group $\mathrm{A}$, $\mathrm{n}=15$, mean $\mathrm{IMT}<0.9 \mathrm{~mm}, \mathrm{ABI} \geq 0.9$; group $\mathrm{B}, \mathrm{n}=25$, mean $\mathrm{IMT}<0.9$ $\mathrm{mm}$, low $\mathrm{ABI}$; group $\mathrm{C}, \mathrm{n}=5$, mean $\mathrm{IMT} \geq 0.9 \mathrm{~mm}, \mathrm{ABI} \geq 0.9$; group $\mathrm{D}, \mathrm{n}=19$, mean IMT $\leq 0.9 \mathrm{~mm}$, low ABI), the presence of significant coronary stenosis $(>50 \%)$ of the groups were significantly different (group $\mathrm{A}, \mathrm{n}=5$ : $(33.3 \%)$; group $\mathrm{B}, \mathrm{n}=11$ : $(52.4 \%)$; group $\mathrm{C}, \mathrm{n}=4$ : $(60 \%)$; group $\mathrm{D}, \mathrm{n}=15,(78.9 \%), \mathrm{P}=0.001$; Figure 2$)$.

\begin{tabular}{cccc}
\hline Total number & \multicolumn{3}{c}{$\mathbf{6 0}$} \\
\hline Age by years (SD) Mean & \multicolumn{5}{c}{ Y4.83 (10.88) } \\
\hline Parameter & $43(71.7 \%)$ & No & P-value \\
\hline Males (\%) & $36(60 \%)$ & $24(40 \%)$ & 0.002 \\
H/O of MI (\%) & $26(43.3 \%)$ & $34(56.7 \%)$ & 0.00 I \\
Dyslipidemia (\%) & $25(41.7 \%)$ & $35(58.3 \%)$ & 0.001 \\
Current smoking (\%) & $33(55 \%)$ & $27(45 \%)$ & 0.003 \\
SWMA (\%) & $27(45 \%)$ & $33(55 \%)$ & 0.001 \\
Diastolic dysfunction (\%) & $24(40 \%)$ & $36(60 \%)$ & 0.008 \\
Mean CIMT > 0.9 mm (\%) & $20(33.3 \%)$ & $40(66.7 \%)$ & 0.139 \\
ABI < 0.9 mm (\%) & $34(56.7 \%)$ & $26(43.3 \%)$ & 0.038 \\
\hline
\end{tabular}

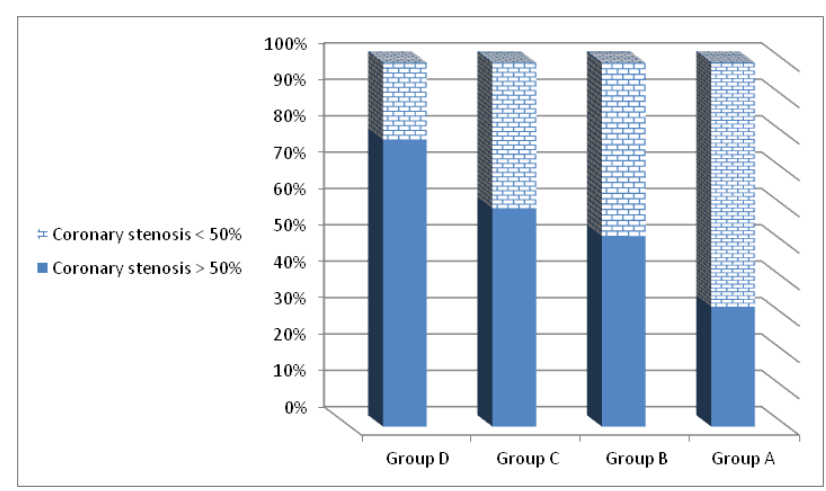

Figure 2 Comparison between the studied groups regarding the degree of coronary stenosis.

\section{Discussion}

The principal finding of the present study was that carotid US results and $\mathrm{ABI}$ are associated with the presence of significant coronary artery disease. Furthermore, the combination of these 2 non-invasive tests makes the prediction of the presence of significant coronary artery disease, more accurate. There is considerable overlap with regard to peripheral artery disease and cardiovascular disease, and previous studies have demonstrated that subjects with low ABI have a considerably higher prevalence of cardiovascular disease than those with normal $\mathrm{ABI} .{ }^{23}$ Additionally, $\mathrm{ABI}$ can predict future coronary events, including total cardiovascular disease and all-cause mortality. ${ }^{24,25}$ There have been no reports, however, concerning the relationship between $\mathrm{ABI}$ and the severity of coronary artery disease. Many previous studies have demonstrated a relationship between carotid US findings and the prevalence or severity of coronary artery 
disease. These investigations have suggested that ABI and IMT could be useful surrogate markers for severity of coronary artery disease, based on the number of diseased coronary arteries, and to predict future cardiovascular events. As far as we know, no studies have investigated the relationship between ABI, carotid US and the severity of coronary artery disease. Therefore, this study was done to present the hypothesis that the evaluation of generalized atherosclerosis by mean IMT and ABI measurement indicates the severity of coronary artery disease. In addition, the combination of the two non-invasive tests provides further precise information regarding lesion complexity, as well as the presence of coronary artery disease.

The mean IMT threshold used in this analysis corresponded to values $\geq 90$ th percentile for most middle-aged men and women in the Atherosclerosis Risk in Communities study. ${ }^{26,27}$ But $40 \%$ of the present patients had mean IMT $>0.9 \mathrm{~mm}$. This finding can be explained by the nature of the present patients, who were candidates for elective coronary angiography. Conversely, we used a cut-off of 0.9 for ABI, according to the definition of the PARTNERS program. $11 \mathrm{ABI}<0.9$ strongly suggests the presence of stenosis of a lower limb artery, but a mean IMT $>0.9 \mathrm{~mm}$ does not equal the presence of stenosis of the carotid artery. Therefore, it is reasonable to hypothesize that a low ABI represents more advanced atherosclerosis than a slightly thicker mean IMT. Only $33.3 \%$ of the present patients had a low ABI $<0.9$, in contrast to the $40 \%$ with a mean IMT $>0.9 \mathrm{~mm}$. Nevertheless, the prevalence of coronary artery disease in patients with a low $\mathrm{ABI}<0.9$ and with a mean IMT $\geq 0.9 \mathrm{~mm}$ was $74.3 \%$ and $54.3 \%$, respectively. The combination of the 2 non-invasive tests provides for better prediction of the presence of significant coronary artery disease.

The REACH registry showed that the presence of polyvascular disease is associated with poor prognosis and is an independent predictor of cardiovascular events. ${ }^{28}$ Furthermore, coronary artery disease with peripheral artery disease and multivessel disease with complex lesion morphology have been more frequently compared with isolated coronary artery disease..$^{29}$ Conversely, recent clinical trials have clearly demonstrated that both the assessment of the classic categories, such as the number of diseased coronary arteries, and the complexity of coronary lesion morphology are useful for predicting major adverse cardiovascular and cerebrovascular events in patients who undergo percutaneous coronary intervention. ${ }^{30,31}$ Taken together, these previous findings seem to support the present findings: that group D (IMT $>0.9 \mathrm{~mm}$ and $\mathrm{ABI}<0.9$ ) was associated with both a greater probability of the presence of coronary artery disease and also with significant coronary artery disease ( $>50 \%$ stenosis). The present study suggests that we can detect both the presence of coronary artery disease and also complex coronary artery lesions using a combination of non-invasive methods. Furthermore, the present findings could be translated into a prediction of future cardiovascular events and may help in decision-making for treatment strategies, such as aggressive risk management and coronary revascularization.

\section{Study limitations}

This study had some limitations. First, the completely occluded part of the carotid artery is not suitable for evaluating mean IMT. This fact may have affected the final results. Second, because the patients enrolled in the present study were candidates for elective coronary angiography, these subjects had a relatively greater risk than the healthy population. Therefore, it is not clear whether the present results would apply when screening the general asymptomatic population (e.g, at a health checkup). Third, the small number of the patient in that study, so, larger number of patients are needed to establish our results. Fourth, the larger number of males as compared to females at our study.

\section{Conclusion}

The combination of mean IMT and ABI provides useful information for predicting the presence of significant coronary artery disease. Large, prospective studies are still necessary to establish the link between these parameters and the complexity of coronary artery disease.

\section{Acknowledgments}

We thank the radiology staff for their excellent technical support.

\section{References}

1. Roig CS, de Winther MP, Weber C, et al. Atherosclerotic plaque destabilization mechanism, models, and therapeutic strategies. Circ Res. 2014;114:214-26.

2. Norgren L, Hiatt WR, Dormandy JA, et al. Trans Atlantic Inter-society Consensus for the management of peripheral arterial disease (TASC II) J Vasc Surg. 2007;45(Suppl S):S5-67.

3. Heald CL, Fowkes FG, Murray GD, et al. Risk of mortality and cardiovascular disease associated with the ankle brachial index: Systematic review. Atherosclerosis. 2006;189(1):61-9.

4. Hirsch AT, Criqui MH, Treat-Jacobson D, et al. Peripheral arterial disease detection, awareness, and treatment in primary care. JAMA. 2001;286(11):1317-24

5. Lamina C, Meisinger C, Heid IM, et al. Association of ankle brachial index and plaques in the carotid and femoral arteries with cardiovascular events and total mortality in a population-based study with 13 years of follow up. Eur Heart J. 2006;27(21):2580-7.

6. Ueki Y, Miura T, Miyashita Y, et al. Predictive value of combining the ankle brachial index and SYNTAX score for the prediction of outcome after percutaneous coronary intervention (from the SHINANO Registry). Am J Cardiol. 2016;117(2):179-85.

7. Chang ST, Chu CM, Hsu JT, et al. Role of ankle-brachial pressure index as a predictor of coronary artery disease severity in patients with diabetes mellitus. Can J Cardiol. 2009;25(9):S301-5.

8. AK Agarwal, Manjeet Singh, Vivek Arya, et al. Prevalence of peripheral Arterial Disease and its correlation with coronary artery disease. JAPI. 2010;60:45-50.

9. Lee AJ, Price JF, Russell MJ, et al. Improved prediction of fatal myocardial infarction using the ankle brachial index in addition to conventional risk factors: the Edinburgh Artery Study. Circulation. 2004;110(19):3075-3080

10. Leng GC, Fowkes FG, Lee AJ, et al. Use of ankle brachial pressure index to predict cardiovascular events and death: a cohort study. BMJ. 1996;313(7070):1440-1444.

11. Papamichael CM, Lekakis JP, Stamatelopoulos KS, et al. Anklebrachial index as a predictor of the extent of coronary atherosclerosis and cardiovascular events in patients with coronary artery disease. $\mathrm{Am} \mathrm{J}$ Cardiol. 2000;86(6):615-618. 
12. Criqui MH, McClelland RL, McDermott MM, et al. The ankle-brachia index and incident cardiovascular events in the MESA (Multi-Ethnic Study of Atherosclerosis). J Am CollCardiol. 2010;56(18):1506-1512.

13. Kasliwal RR, Bansal M, Gupta H, et al. Association of carotid intimamedia thickness with left main coronary artery disease. Indian Heart $J$ 2007;59(1):50-55

14. Wang D, Yang H, Quinones MJ, et al. A genome-wide scan for carotid artery intima-media thickness: the Mexican - American Coronary Artery Disease Family Study. Stroke. 2005;36(3):540-545.

15. Liviakis L, Pogue B, Paramsothy P, et al. Carotid intima-media thickness for the practicing lipidologist. J ClinLipidol. 2010;4(1):24-35.

16. Kablak-Ziembicka A, Tracz W, Przewlocki T, et al. Association of increased carotid intima- media thickness with the extent of coronary artery disease. Heart. 2004;90(11):1286-1290.

17. Heuten H, Goovaerts I, Ennekens G, et al. Carotid artery intima- media thickness is associated with coronary artery disease. Acta Cardiol. 2008;63(3):309-313.

18. Hayashi $\mathrm{C}$, Ogawa $\mathrm{O}$, Kubo S, et al. Ankle brachial pressure index and carotid intima- media thickness as atherosclerosis markers in Japanese diabetics. Diabetes Res ClinPract. 2004;66(3):269-275

19. Pignoli P, Tremoli E, Poli A, et al. Intimal plus media 1 thickness of the arterial wall: a direct measurement with ultrasound imag ing. Circulation. 1986;74(6):1399-1406.

20. Greenland P, Alpert JS, Beller Ga, et al. 2010 ACCF/AHA guideline for assessment of cardiovascular risk in asymptomatic adults: a report of the American College of Cardiology Foundation/American Heart Association Task Force on Practice Guidelines. J Am Coll Cardiol. 2010;56(25):e50-e103.

21. Stein JH, Korcarz CE, Hurst RT, et al. Use of carotid ultrasound to identify subclinical vascular dis-ease and evaluate cardiovascular disease risk: A consensus statement from the American Society of Echocardiography Carotid Intima-Media Thickness Task Force: Endorsed by the Society for Vascular Medicine. J Am Soc Echocardiogr. 2008;21(2):93-111.

22. Weintraub WS, Karlsberg RP, Tcheng JE, et al. ACCF/AHA 2011 key data elements and definitions of a base cardiovascular vocabulary for electronic health records: a report of the American College of Cardiology Foundation/American Heart Association Task Force on Clinical Data Standards. J Am Coll Cardiol. 2011;124(1):103-23.

23. Criqui $\mathrm{MH}$, Denenberg JO, Langer RD, et al. The epidemiology of peripheral arterial disease: Importance of identifying the population at risk. Vasc Med. 1997;2(3):221-226.

24. McKenna M, Wolfson S, Kuller L. The ratio of ankle and arm arteria pressure as an independent predictor of mortality. Atherosclerosis. 1991;87(2-3):119-128.

25. Criqui MH, Langer RD, Fronek A, et al. Mortality over a period of 10 years in patients with peripheral arterial disease. $N$ Engl J Med. 1992;326(6):381-386.

26. Ikeda N, Kogame N, Iijima R, et al. Carotid artery intima-media thickness and plaque score can predict the SYNTAX score. Eur Heart J. 2012;33(1):113-119.

27. Howard G, Burke GL, Evans GW, et al. Relations of intimal-medial thickness among sites within the carotid artery as evaluated by B-mode ultrasound: ARIC Investigators: Atherosclerosis Risk in Communities. Stroke. 1994;25(8):1581-1587.

28. Cacoub PP, Abola MT, Baumgartner I, et al. Cardiovascular risk factor control and outcomes in peripheral artery disease patients in the Reduction of Atherothrombosis for Continued Health (REACH) Registry. Atherosclerosis. 2009;204(2):e86-e92.

29. Singh M, Lennon RJ, Darbar D, et al. Effect of peripheral arterial disease in patients undergoing percutaneous coronary intervention with intracoronary stents. Mayo Clin Proc. 2004;79(9):1113-1118.

30. Morice MC, Serruys PW, Kappetein AP, et al. Outcomes in patients with de novo left main disease treated with either percutaneous coronary intervention using paclitaxel-eluting stents or coronary artery bypass graft treatment in the Synergy Between Percutaneous Coronary Intervention with TAXUS and Cardiac Surgery (SYNTAX) trial. Circulation. 2010;121(24):2645-2653.

31. Valgimigli M, Serruys PW, Tsuchida K, et al. Cyphering the complexity of coronary artery disease using the syntax score to predict clinical outcome in patients with three-vessel lumen obstruction undergoing percutaneous coronary intervention. Am J Cardiol. 2007;99(8):1072-1081. 